Supporting information for

\title{
Effect of Water Adsorption on the Photoluminescence of Silicon Quantum Dots
}

\author{
Jinrong Yang, ${ }^{\dagger, \S}$ Haiping Fang ${ }^{\dagger, \ddagger}$ and Yi Gao ${ }^{*}, \dagger, \ddagger$ \\ ${ }^{\dagger}$ Division of Interfacial Water and Key Laboratory of Interfacial Physics and \\ Technology, Shanghai Institute of Applied Physics, Chinese Academy of Sciences, \\ Shanghai 201800, China \\ ${ }^{\ddagger}$ Shanghai Science Research Center, Chinese Academy of Sciences, Shanghai 201204, \\ China \\ ${ }^{\S}$ University of Chinese Academy of Sciences, Beijing 100049, China \\ Corresponding Author \\ *E-mail: gaoyi@sinap.ac.cn
}

\section{Content}

PS1. The benchmark calculations of several small-size silicon cluster for the basis sets 6-31G(d)

PS2. The most stable geometry optimized structures of $\mathrm{Si}$ QDs $\left(\mathrm{Si}_{32} \mathrm{H}_{38}\right)$ in vacuum and with water clusters adsorption

PS3. The discussion of water affecting the absorption spectra

PS4. The distribution of Si-Si bond lengths of Si QDs in vacuum and with water clusters adsorption in ground states and excited states

PS5. The mechanism of water cluster changing the Si-Si dimer distance

PS6. Electronic transition orbits in excited states for $\left(\mathrm{H}_{2} \mathrm{O}\right)_{1},\left(\mathrm{H}_{2} \mathrm{O}\right)_{2},\left(\mathrm{H}_{2} \mathrm{O}\right)_{4}$ and $\left(\mathrm{H}_{2} \mathrm{O}\right)_{5}$ adsorption on Si QDs

PS7. The PL spectra of large size of Si QDs $\left(\mathrm{Si}_{43} \mathrm{H}_{48}\right)$ 
PS1. The benchmark calculations of several small-size silicon cluster for the basis sets 6-31G(d)

Several small-size silicon clusters were calculated at the TDDFT/B3LYP level with the basis sets $6-31+\mathrm{G}(\mathrm{d}), 6-31+\mathrm{G}(\mathrm{d}, \mathrm{p})$ and $6-31++\mathrm{G}(\mathrm{d}, \mathrm{p})$ in the benchmark calculations. As shown in Table S1, the absorption energies with the basis sets 6-31G(d) are in agreement with those of the large basis sets.

Table S1. Comparison of calculated absorption energy $E_{\text {abs }}(\mathrm{eV})$ of several small-size silicon clusters with the diffuse functions added to basis sets.

\begin{tabular}{lccccc}
\hline cluster & $6-31 \mathrm{G}(\mathrm{d})$ & $6-31+\mathrm{G}(\mathrm{d})$ & $6-31+\mathrm{G}(\mathrm{d}, \mathrm{p})$ & $6-31++\mathrm{G}(\mathrm{d}, \mathrm{p})$ & expt \\
\hline $\mathrm{SiH}_{4}$ & 9.62 & 8.78 & 8.75 & 8.65 & $8.8^{1}$ \\
$\mathrm{Si}_{2} \mathrm{H}_{6}$ & 7.72 & 7.51 & 7.47 & 7.42 & $7.6^{1}$ \\
$\mathrm{Si}_{3} \mathrm{H}_{8}$ & 7.08 & 6.95 & 6.92 & 6.87 & $6.6^{1}$ \\
$\mathrm{Si}_{5} \mathrm{H}_{12}$ & 6.61 & 6.47 & 6.19 & 6.17 & $6.5^{2}$ \\
$\mathrm{Si}_{10} \mathrm{H}_{16}$ & 5.92 & 5.67 & 5.66 & 5.63 & \\
$\mathrm{Si}_{2} \mathrm{H}_{36}$ & 4.61 & 4.52 & 4.52 & 4.51 &
\end{tabular}

PS2. The most stable geometry optimized structures of $\mathrm{Si}$ QDs $\left(\mathrm{Si}_{32} \mathrm{H}_{38}\right)$ in vacuum and with water clusters adsorption

Firstly, for water clusters adsorption on Si QDs, we tried various starting structures to find out the most stable geometry optimized structures in ground state. Here, the most stable geometries of water clusters $\left(\mathrm{H}_{2} \mathrm{O}\right)_{n}$, where $n$ is 1-5 and 10 , refer to the previous studies $^{3}$, as shown in Figure S1. From these initial structures, numerous local stable geometry optimized structures were obtained. Table S2 presents one examples of $\left(\mathrm{H}_{2} \mathrm{O}\right)_{3}$ adsorption on $\mathrm{Si}$ QDs, which lists six local stable structures.

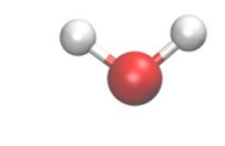

$\left(\mathrm{H}_{2} \mathrm{O}\right)_{1}$

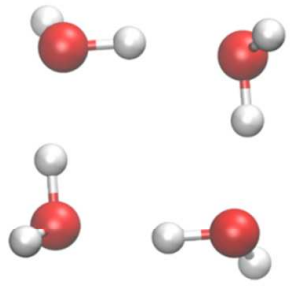

$\left(\mathrm{H}_{2} \mathrm{O}\right)_{4}$
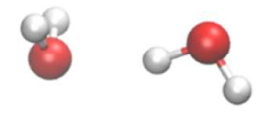

$\left(\mathrm{H}_{2} \mathrm{O}\right)_{2}$

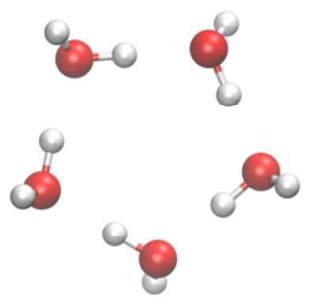

$\left(\mathrm{H}_{2} \mathrm{O}\right)_{5}$

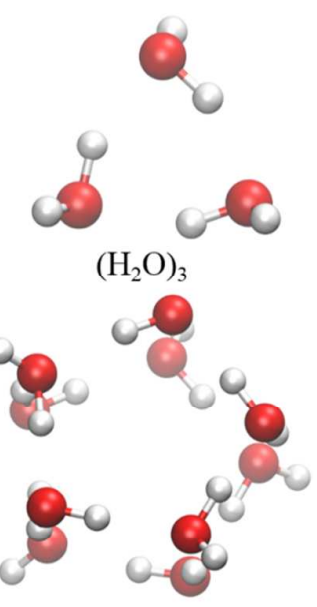

$\left(\mathrm{H}_{2} \mathrm{O}\right)_{10}$

Figure S1. The most stable geometries of water clusters.

Because the electronegativity of hydrogen (2.1) is slightly larger than that of silicon (1.9), the hydrogen atoms will carry negative charges. For example, according to the 
Mulliken charges of $\left(\mathrm{H}_{2} \mathrm{O}\right)_{3}$ adsorption on $\mathrm{Si}$ QDs shown in Figure $\mathrm{S} 2(\mathrm{a})$, the magnitude of negatively charged hydrogen is -0.072 while its neighboring $\mathrm{Si}$ atoms have positive charges. Thus, the hydrogen atoms of Si QDs can behave as an acceptor to form a weak bond defined as $\mathrm{H}-\mathrm{O}-\mathrm{H}{ }^{\cdots \cdots} \mathrm{H}-\mathrm{Si}$. This weak bond favors the two hydrogen atoms of water molecule toward the hydrogen atoms of Si QDs, which tend to force the water molecule parallel to the surface. This phenomenon was also observed by these papers. $^{4-7}$

Considering to the weak interaction between the water molecule and Si QDs, we have further analyzed this weak interaction by reduced density gradient (RDG) method. ${ }^{8}$ As shown in Figure S2(b), although some hydrogen atoms of $\left(\mathrm{H}_{2} \mathrm{O}\right)_{3}$ do not point toward the hydrogen atom of the surface of Si QDs, van der Waals interaction exists between water molecule and Si QDs. For such weak interaction, the van der Waals interaction is significant in determining a nearly flat adsorption orientation of water clusters at the surface of Si QDs.

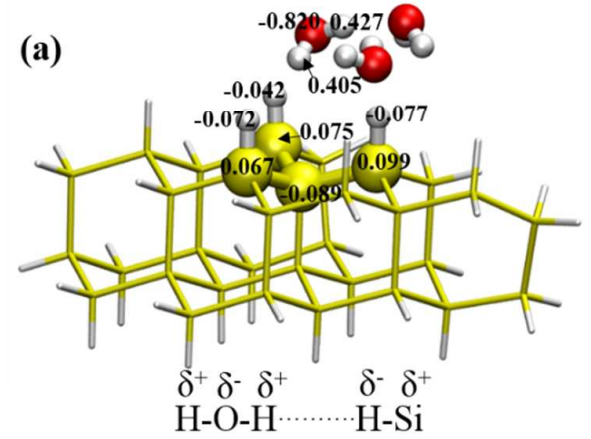

(b)

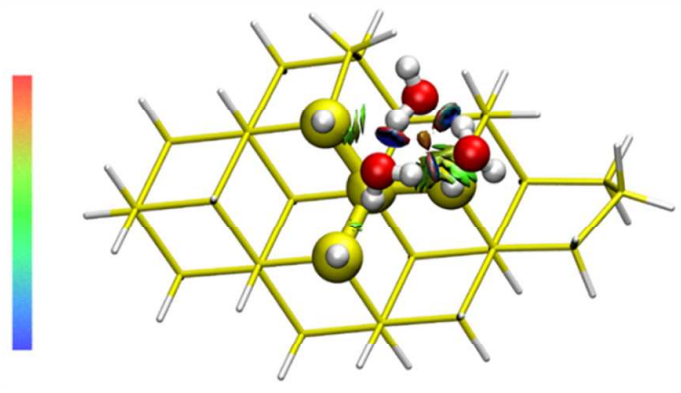

Figure S2. (a) Mulliken charge of $\left(\mathrm{H}_{2} \mathrm{O}\right)_{3}$ adsorption on Si QDs. (b) Appearance of the intermolecular interaction region in the $\left(\mathrm{H}_{2} \mathrm{O}\right)_{3}$ adsorption on Si QDs. The blue, green and red regions represent the hydrogen bond interaction, van der Waals interaction and steric effect in ring and cage. The hydrogen-terminated $\mathrm{Si}$ cluster $\left(\mathrm{Si}_{32} \mathrm{H}_{38}\right)$ is shown by light yellow line, except the $\mathrm{Si}$ atoms involved the orientation of water molecules shown as yellow spheres. The hydrogen atom of water molecule is shown by white sphere, and the oxygen atoms of water are shown by red spheres.

In addition, the electric dipole moment of water molecules are shown to reveal the orientation of water clusters at the surface of Si QDs in the Figure S3. For a single water molecule, its hydrogen atoms bridge two nearest-neighboring surface hydrogen atoms of Si QDs. Similarly, the orientation of $\left(\mathrm{H}_{2} \mathrm{O}\right)_{2}$ is also parallel to the surface. For $\left(\mathrm{H}_{2} \mathrm{O}\right)_{3}$, one water molecule bridges a nearest-neighboring hydrogen atom while an interior $\mathrm{Si}$ atom with negatively charge leads to negatively charged water $\mathrm{O}$ atoms away from the surface. Two nearest-neighboring surface hydrogen atoms of Si QDs and an interior $\mathrm{Si}$ atom determine the adsorption orientation of $\left(\mathrm{H}_{2} \mathrm{O}\right)_{4}$. The adsorption orientation of $\left(\mathrm{H}_{2} \mathrm{O}\right)_{5}$ and $\left(\mathrm{H}_{2} \mathrm{O}\right)_{10}$ origin from the three nearest-neighboring surface 
hydrogen atoms of Si QDs.
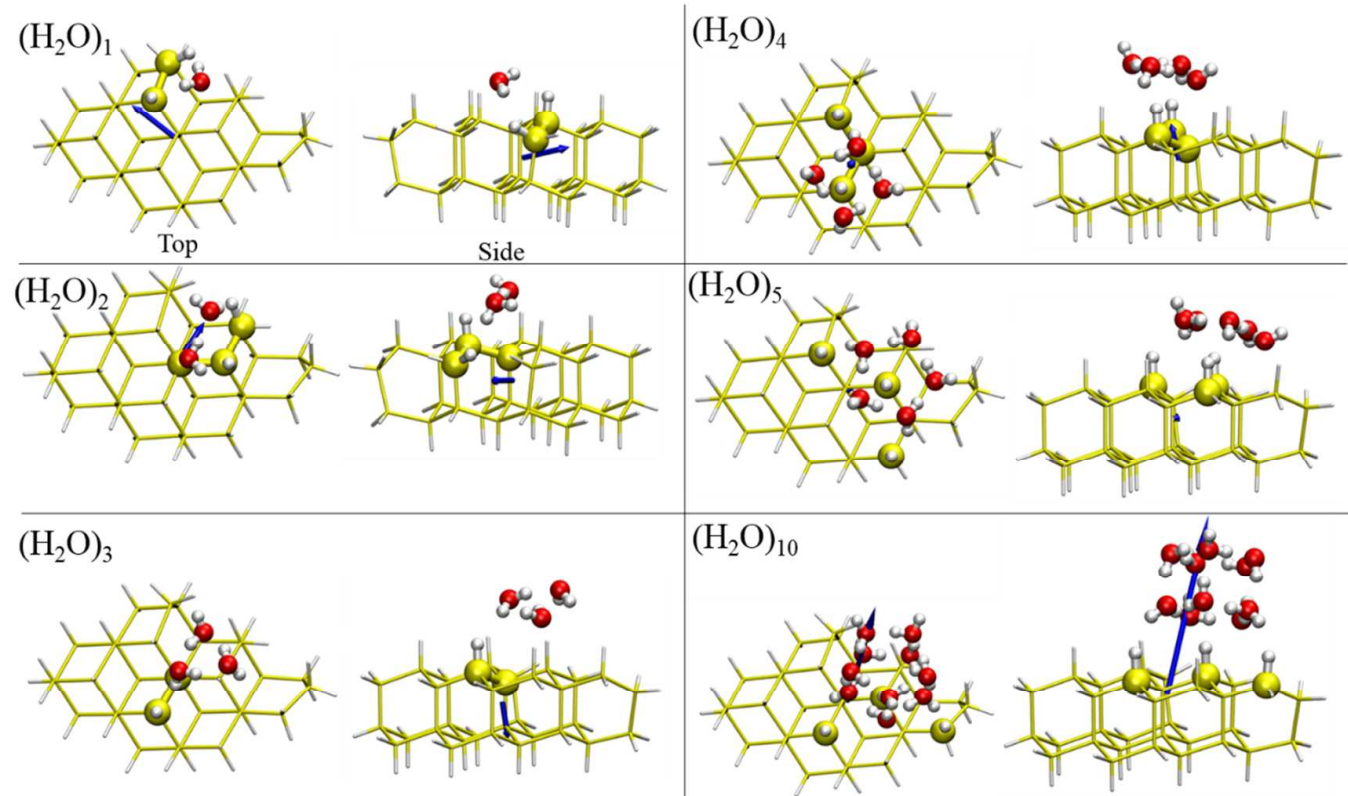

Figure S3. The blue thick arrows represent the orientation of water clusters at the surface of Si QDs. Color settings are the same as the Figure S2.

Therefore, the adsorption orientation of water clusters attached to the surface of $\mathrm{Si}$ QDs can be understood from the delicate balance between the electrostatic interactions a weak bond defined as $\mathrm{H}-\mathrm{O}-\mathrm{H}{ }^{\cdots \cdots} \mathrm{H}-\mathrm{Si}$, the surface $\mathrm{Si}$ atoms and the interior Si atoms.

Table S2. One examples for searching the most stable geometry optimized structures of $\left(\mathrm{H}_{2} \mathrm{O}\right)_{3}$ adsorption on $\mathrm{Si}$ QDs. Therein, six local stable structures are listed in order of increasing system energy from left to right. The corresponding energy difference follows below each local stable structure, $\Delta E=$ $E_{\text {config }}-E_{\text {min }}$, where $E_{\text {config }}$ represents the energy of local stable structures and $E_{\min }$ is the lowest energy for $\left(\mathrm{H}_{2} \mathrm{O}\right)_{3}$ adsorption on $\mathrm{Si}$ QDs.

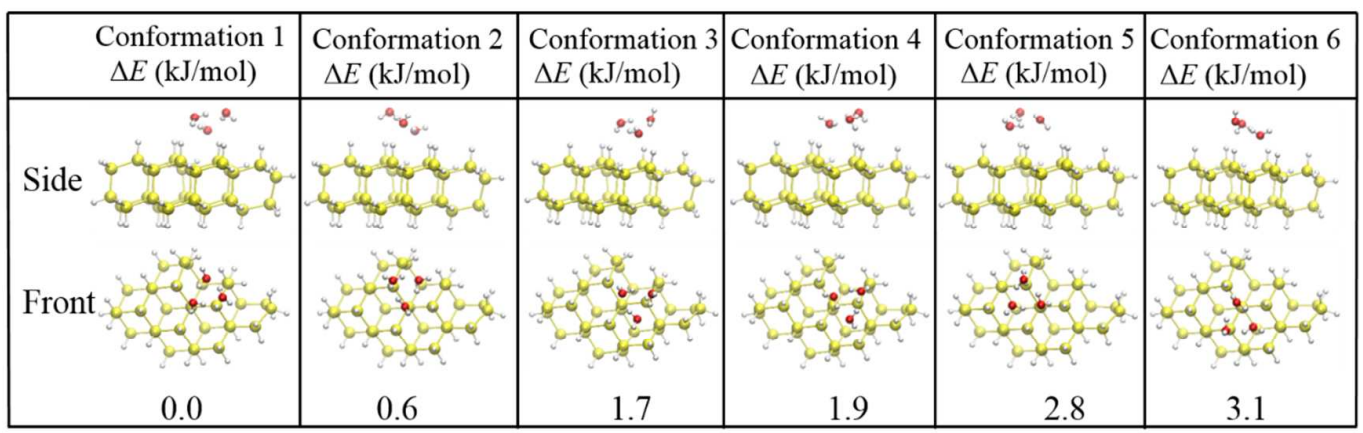

we have shown top three lowest-energy configurations (total six configurations considered each) with $\left(\mathrm{H}_{2} \mathrm{O}\right)_{1},\left(\mathrm{H}_{2} \mathrm{O}\right)_{2},\left(\mathrm{H}_{2} \mathrm{O}\right)_{4},\left(\mathrm{H}_{2} \mathrm{O}\right)_{5}$ and $\left(\mathrm{H}_{2} \mathrm{O}\right)_{10}$ adsorption on $\mathrm{Si}$ 
QDs in the Table S3.

Table S3. Three local stable structures are listed in order of increasing system energy from left to right. The corresponding energy difference follows below each local stable structure, $\Delta E=E_{\text {config }}-E_{\text {min }}$, where $E_{\text {config }}$ represents the energy of local stable structures and $E_{\min }$ is the lowest energy for water clusters adsorption on Si QDs.

\begin{tabular}{|c|c|c|c|}
\hline & $\begin{array}{c}\text { Conformation 1 } \\
\Delta E(\mathrm{~kJ} / \mathrm{mol})\end{array}$ & $\begin{array}{l}\text { Conformation } 2 \\
\Delta E(\mathrm{~kJ} / / \mathrm{mol})\end{array}$ & $\begin{array}{l}\text { Conformation } 3 \\
\Delta E(\mathrm{~kJ} / \mathrm{mol}) \\
\end{array}$ \\
\hline$\left(\mathrm{H}_{2} \mathrm{O}\right)_{1}$ & ${ }_{0.0}<q$ & & \\
\hline$\left(\mathrm{H}_{2} \mathrm{O}\right)_{2}$ & & & \\
\hline$\left(\mathrm{H}_{2} \mathrm{O}\right)_{4}$ & & & \\
\hline$\left(\mathrm{H}_{2} \mathrm{O}\right)_{5}$ & 0.0 & 1.2. & \\
\hline$\left(\mathrm{H}_{2} \mathrm{O}\right)_{10}$ & & & \\
\hline
\end{tabular}

\section{PS3. The discussion of water affecting the absorption spectra}

As shown in Figure $\mathrm{S} 4$, the weak electric dipole moment $(0.1)$ of $\mathrm{Si}_{32} \mathrm{H}_{38}$ in ground state results in the small adsorption energy of water clusters on $\mathrm{Si}_{32} \mathrm{H}_{38}$ (Table S4) and the resemblance of the HOMO and LUMO density (Figure S5), which leads to the similar characteristics of adsorption spectra. However, large enhancement of electric dipole moment (4.4) from exciton in $\mathrm{Si}_{32} \mathrm{H}_{38}$ induced by photo excitation can strongly be coupled to the water clusters on the surface of $\mathrm{Si}_{32} \mathrm{H}_{38}$ to induce the different characteristics of PL spectra. 


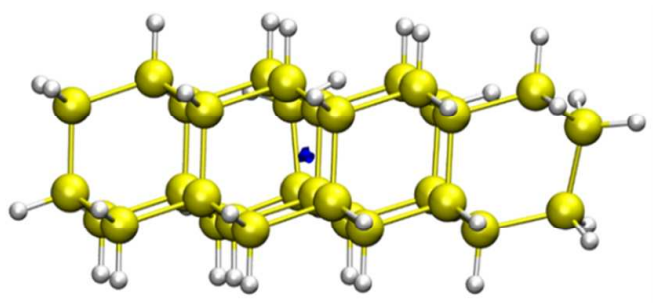

Ground state $(\mu=0.1)$

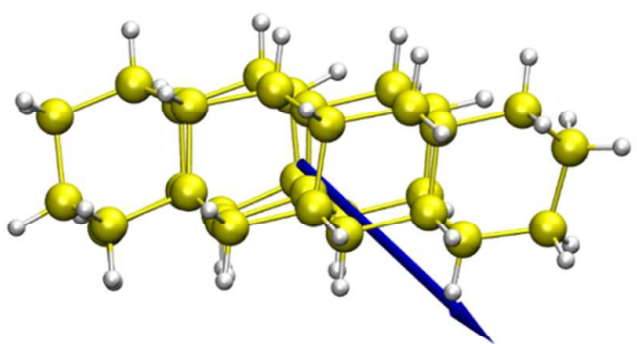

Excited state $(\mu=4.4)$

Figure S4. Electric dipole moment $(\mu)$ of vacuum Si cluster in ground and excited state. The blue thick arrows represent the direction of $\mu$, and the unit of it is Debye. Color settings are same as the Figure S2.

As can be seen in Table S4, the adsorption energy of $\left(\mathrm{H}_{2} \mathrm{O}\right)_{1}$ is $0.19 \mathrm{eV}$. The surface adsorption energy even decreases upon $\left(\mathrm{H}_{2} \mathrm{O}\right)_{3}$ and $\left(\mathrm{H}_{2} \mathrm{O}\right)_{4}$ adsorption on the surface of Si QDs. With increasing water molecules to $\left(\mathrm{H}_{2} \mathrm{O}\right)_{5}$ and $\left(\mathrm{H}_{2} \mathrm{O}\right)_{10}$, the adsorption energy is only $\sim 0.25 \mathrm{eV}$. Water adsorption on the $\mathrm{Si}$ clusters is in the weak physisorption limit leading to a hydrophobic surface. ${ }^{5,7}$ Lange et al. have shown that water molecules adsorption on the hydrogenated $\mathrm{Si}(111)$ is the weak interaction, with small adsorption energies of several $\mathrm{meV}^{5}$

Table S4. The adsorption energy ( $\left.\Delta E_{\text {adr }}\right)$ of water cluster on the surface of Si QDs. $\Delta E_{\mathrm{adr}}$ is defined as: $\Delta E_{\mathrm{adr}}=E_{\mathrm{w}}+E_{\mathrm{Si}}-E_{\mathrm{w}-\mathrm{Si}}$. Here, $E_{\mathrm{w}}, E_{\mathrm{Si}}$ and $E_{\mathrm{w}-\mathrm{si}}$ were the total energies of the water clusters, the $\mathrm{Si}$ QDs, and the water cluster adsorbed on $\mathrm{Si}$ QDs, respectively.

\begin{tabular}{c|c|c|c|c|c|c}
\hline cluster & $\left(\mathrm{H}_{2} \mathrm{O}\right)_{1}$ & $\left(\mathrm{H}_{2} \mathrm{O}\right)_{2}$ & $\left(\mathrm{H}_{2} \mathrm{O}\right)_{3}$ & $\left(\mathrm{H}_{2} \mathrm{O}\right)_{4}$ & $\left(\mathrm{H}_{2} \mathrm{O}\right)_{5}$ & $\left(\mathrm{H}_{2} \mathrm{O}\right)_{10}$ \\
\hline$\Delta E_{\text {adr }}(\mathrm{eV})$ & 0.19 & 0.22 & 0.18 & 0.18 & 0.29 & 0.25 \\
\hline
\end{tabular}



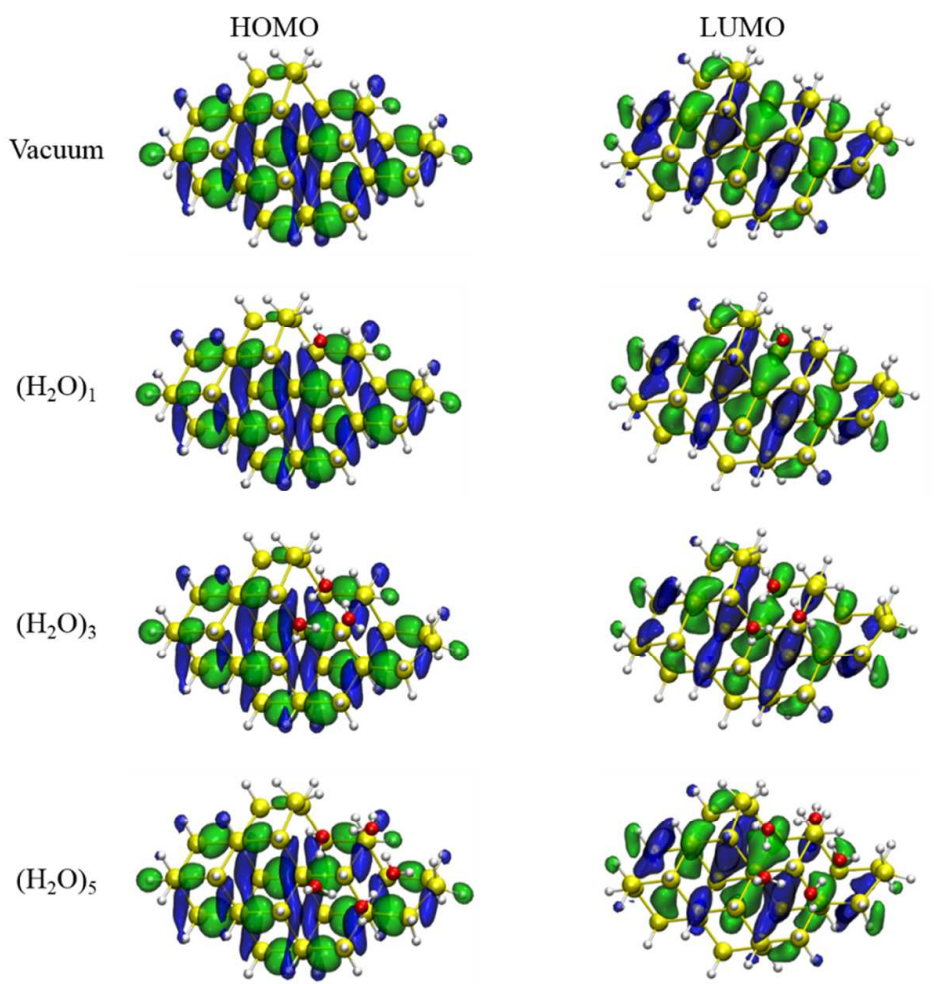

Figure S5. HOMO and LUMO of vacuum Si cluster, $\left(\mathrm{H}_{2} \mathrm{O}\right)_{1},\left(\mathrm{H}_{2} \mathrm{O}\right)_{3}$ and $\left(\mathrm{H}_{2} \mathrm{O}\right)_{5}$ adsorption on Si cluster in ground state. Wave function isosurfaces were plotted at the same isovalue, where the blue and green areas denote the signs $( \pm)$, respectively. Color settings are same as the Figure $\mathbf{S 2}$.

PS4. The distribution of $\mathrm{Si}-\mathrm{Si}$ bond lengths of $\mathrm{Si}$ QDs in vacuum and with water clusters adsorption in ground states and excited states 

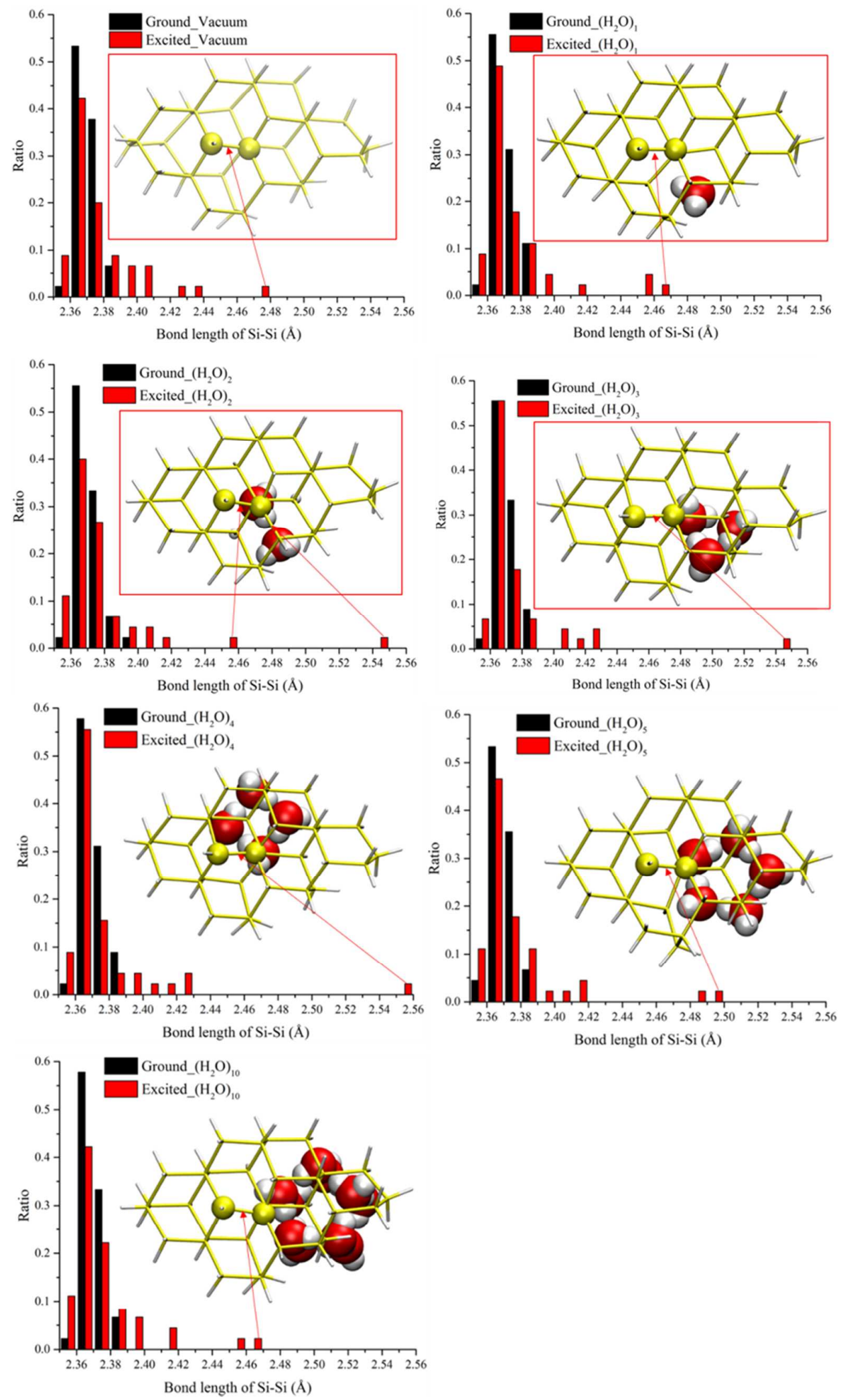

Figure S6. Comparison of the Si-Si bond lengths distribution of vacuum Si QDs and water clusters adsorption on Si QDs in the ground state geometry (black 
histogram) and in the relaxed excited state geometry (red histogram). The insets show schematic geometrical relaxation diagram of the $\mathrm{Si}_{32} \mathrm{H}_{38}$ in excited-state configuration, and the thick arrows represent the largest stretched bond. The hydrogen-terminated $\mathrm{Si}$ cluster $\left(\mathrm{Si}_{32} \mathrm{H}_{38}\right)$ is shown by light yellow line, and the $\mathrm{Si}$ atoms in this Si-Si bond are shown as yellow spheres. The hydrogen atoms of water molecule are shown by white sphere, and the oxygen atoms of water molecule are shown by red spheres.

Figure $\mathrm{S} 6$ shows the $\mathrm{Si}-\mathrm{Si}$ bond lengths distribution of $\mathrm{Si}_{32} \mathrm{H}_{38}$ for vacuum $\mathrm{Si}$ QDs and water clusters adsorption on Si QDs in the ground state geometry and in the relaxed excited state geometry, and the insets show the detail stretched bond of the $\mathrm{Si}_{32} \mathrm{H}_{38}$ in excited-state configuration. In the vacuum environment, we see that it is similar in the ground state and in the excited state with the maxima center at $2.37 \AA$ (bulk Si-Si bond length), except for a single $\mathrm{Si}-\mathrm{Si}$ bond is stretched by about $2.48 \AA$ in the excited state geometry, as shown in the inset of Figure S6. Using ab initio density functional methods, Franceschetti and Pantelides ${ }^{9}$ also demonstrated that a single Si-Si bond in the interior of the nanocrystal $\left(\mathrm{Si}_{29} \mathrm{H}_{36}\right)$ is stretched by about $15 \%$ in the excited-state geometry, because local density approximation (LDA) tends to overestimate bond strengths ${ }^{10}$. In this TDDFT calculations, the results show that excited state relaxations lead to the formation of a stretched bond in the surface of this Si QDs, which is consistent with that in small hydrogen-passivated Si QDs, excitons can become self-trapped in stable states localized at the surface ${ }^{11}$. Actually, the distribution of $\mathrm{Si}-\mathrm{Si}$ bond lengths for $\left(\mathrm{H}_{2} \mathrm{O}\right)_{1}$ adsorption on $\mathrm{Si}$ QDs shows only a single $\mathrm{Si}-\mathrm{Si}$ bond stretched by about $2.46 \AA$ in the excited state geometry. For $\left(\mathrm{H}_{2} \mathrm{O}\right)_{2}$ adsorption on $\mathrm{Si}$ QDs, a single Si-Si bond stretched by about $2.46 \AA$ in the excited state geometry is not only shown, but also another Si-Si bond stretched by about $2.54 \AA$ is seen in the insets, which suggests that these solvent polarization impact the surface structure of excited state geometry. But, for the $\left(\mathrm{H}_{2} \mathrm{O}\right)_{3}$ and $\left(\mathrm{H}_{2} \mathrm{O}\right)_{4}$, the bond length of this $\mathrm{Si}-\mathrm{Si}$ dimer extends from 2.38 to $2.54 \AA$ under excitation, which is stretched about $0.16 \AA$. Contrary to the large stretch of $\left(\mathrm{H}_{2} \mathrm{O}\right)_{3}$ and $\left(\mathrm{H}_{2} \mathrm{O}\right)_{4}$, with the $\left(\mathrm{H}_{2} \mathrm{O}\right)_{5}$ and $\left(\mathrm{H}_{2} \mathrm{O}\right)_{10}$ adsorption on $\mathrm{Si}$ QDs, this $\mathrm{Si}-\mathrm{Si}$ dimer distances of excited-state configurations only show an extension about $0.1 \AA$. Therefore, the stretched bond should depend on the surround environment.

\section{PS5. The mechanism of water cluster changing the Si-Si dimer distance}

Large enhancement of electric dipole moment (4.4 for $\mathrm{Si}_{32} \mathrm{H}_{38}$ ) from exciton in $\mathrm{Si}$ QDs induced by photo excitation can strongly be coupled to the water clusters on the surface of Si QDs, which results in the electron localized, and then the Si-Si dimer distance is changed. The various changes of the $\mathrm{Si}-\mathrm{Si}$ dimer distances with water clusters adsorption origin from the different orientation of electric dipole moment with water clusters adsorption on Si QDs.

In the Figure S7, the direction of dipole moment vector in $\left(\mathrm{H}_{2} \mathrm{O}\right)_{1}$ adsorption on the 
surface $\mathrm{Si}_{32} \mathrm{H}_{38}$ is parallel to the surface of $\mathrm{Si}_{32} \mathrm{H}_{38}$, while the direction of dipole moment vector in $\left(\mathrm{H}_{2} \mathrm{O}\right)_{3}$ and $\left(\mathrm{H}_{2} \mathrm{O}\right)_{10}$ adsorption on the surface $\mathrm{Si}_{32} \mathrm{H}_{38}$ is perpendicular to the surface of $\mathrm{Si}_{32} \mathrm{H}_{38}$. Upon a single water molecule adsorption on $\mathrm{Si}_{32} \mathrm{H}_{38}$, Figure $\mathrm{S} 7$ shows that the electron of lowest unoccupied molecular orbital (LUMO) in the excited state is localized around the surface $\mathrm{Si}$ atoms. The structure of $\left(\mathrm{H}_{2} \mathrm{O}\right)_{3}$ attached to the Si QDs is treated as a typical case which shows a localized distribution of the LUMO along the central stretched $\mathrm{Si}$-Si dimer, due to a significant extension 2.38 to $2.54 \AA$. In the case of humid environment, such as $\left(\mathrm{H}_{2} \mathrm{O}\right)_{10}$, LUMO is localized on the several $\mathrm{Si}$ atoms at the edge of $\mathrm{Si}_{32} \mathrm{H}_{38}$. Comparison of the orientation of electric dipole moment with $\left(\mathrm{H}_{2} \mathrm{O}\right)_{1},\left(\mathrm{H}_{2} \mathrm{O}\right)_{3}$ and $\left(\mathrm{H}_{2} \mathrm{O}\right)_{10}$ adsorption on $\mathrm{Si}_{32} \mathrm{H}_{38}$, it suggests that the direction of LUMO is drastically influenced by water molecules, and then changes the Si-Si dimer distances.

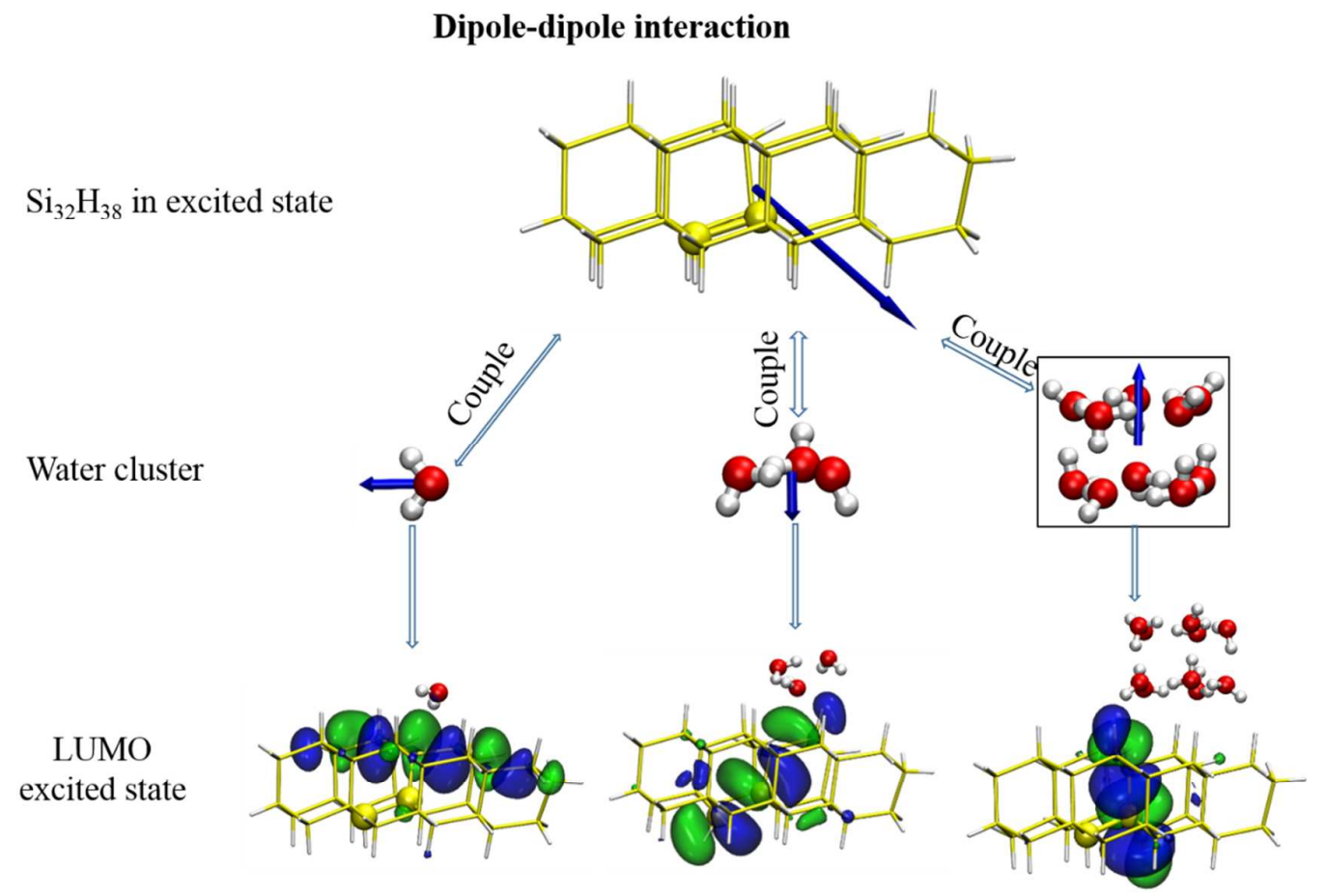

Figure S7. Dipole moment of water clusters inducing electron localized of water clusters adsorption on the surface of $\mathrm{Si}_{32} \mathrm{H}_{38}$ in excited state. The orientation of electric dipole moment is represented by blue thick arrow. Color settings are same as the Figure S2.

PS6. Electronic transition orbits in excited states for $\left(\mathrm{H}_{2} \mathrm{O}\right)_{1},\left(\mathrm{H}_{2} \mathrm{O}\right)_{2},\left(\mathrm{H}_{2} \mathrm{O}\right)_{4}$ and $\left(\mathrm{H}_{2} \mathrm{O}\right)_{5}$ adsorption on Si QDs 


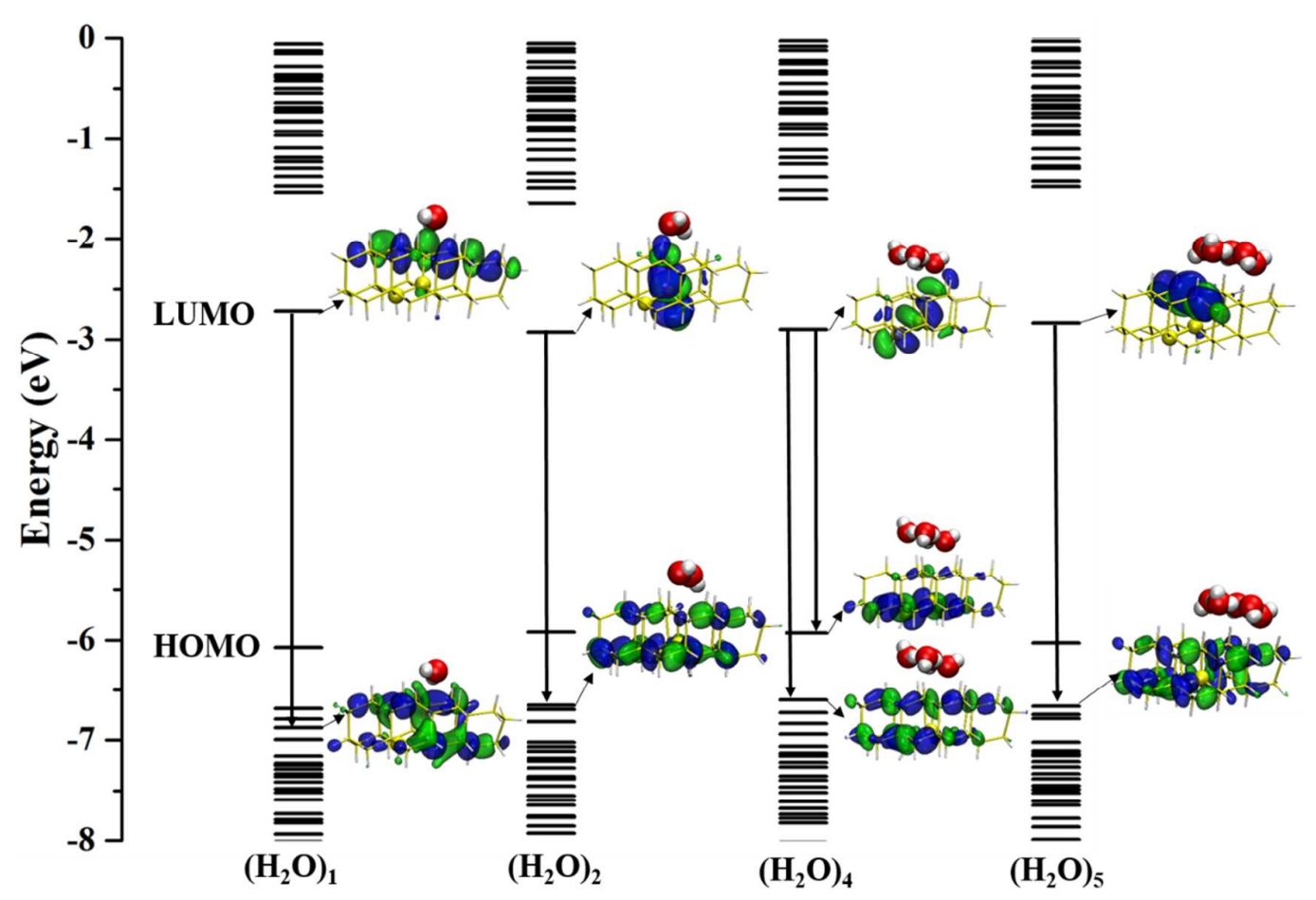

Figure S8. Electronic transition orbits in excited states for vacuum $\left(\mathrm{H}_{2} \mathrm{O}\right)_{1}$, $\left(\mathrm{H}_{2} \mathrm{O}\right)_{2}\left(\mathrm{H}_{2} \mathrm{O}\right)_{4}$, and $\left(\mathrm{H}_{2} \mathrm{O}\right)_{5}$ adsorption on $\mathrm{Si}$ QDs. Wave function isosurfaces were plotted at the same isovalue, where the blue and green areas denote the signs $( \pm)$, respectively. The thick arrows represent the electron transition in excited state. The hydrogen terminated $\mathrm{Si}$ QDs $\left(\mathrm{Si}_{32} \mathrm{H}_{38}\right)$ is shown by light yellow line, and the $\mathrm{Si}$ atoms in the $\mathrm{Si}-\mathrm{Si}$ dimer are shown as yellow spheres. Oxygen atoms and hydrogen atoms in water molecule are shown by red and white, respectively.

\section{PS7. The PL spectra of large size of $\mathrm{Si}$ QDs $\left(\mathrm{Si}_{43} \mathrm{H}_{48}\right)$}

In order to check the impact of the size of Si QDs, we have performed simulations using $\mathrm{Si}_{43} \mathrm{H}_{48}$ to compute the absorption spectra and fluorescence spectra of water cluster adsorption on this cluster with the size of around $1.2 \mathrm{~nm}$. In contrast to the negligible impact on the absorption spectra with $\left(\mathrm{H}_{2} \mathrm{O}\right)_{1}$ adsorption on $\mathrm{Si}_{43} \mathrm{H}_{48}$, the fluorescence spectra of with the peak position at $\sim 367 \mathrm{~nm}$ show a red-shift about 10 nm compared to $\mathrm{Si}_{43} \mathrm{H}_{48}$ in the vacuum environment. Meanwhile, we also find the existence of a dual fluorescence with maxima centered at $\sim 356 \mathrm{~nm}$ and $\sim 470 \mathrm{~nm}$ in the $\left(\mathrm{H}_{2} \mathrm{O}\right)_{3}$ adsorption on $\mathrm{Si}_{43} \mathrm{H}_{48}$. This suggests that our results can be extended for other larger size of Si QDs.

In the Figure S9(a), although there are little different intensity of the absorption peak, the absorption wavelengths of $\mathrm{Si}_{43} \mathrm{H}_{48}$ in the vacuum and water cluster molecules adsorption are all centered on $\sim 297 \mathrm{~nm}$. This suggests that there is also negligible impact of water molecules on the optical absorption of $\mathrm{Si}_{43} \mathrm{H}_{48}$. As the fluorescence spectra of vacuum $\mathrm{Si}_{43} \mathrm{H}_{48}$ shown in Figure $\mathrm{S} 9(\mathrm{~b})$, the feature appears as the main 
peak at $\sim 356 \mathrm{~nm}$ with the oscillator strength of 0.0067 . The resemblance of these features exists in the fluorescence spectra of $\left(\mathrm{H}_{2} \mathrm{O}\right)_{1}$ adsorption on $\mathrm{Si}_{43} \mathrm{H}_{48}$. In the case of $\left(\mathrm{H}_{2} \mathrm{O}\right)_{3}$ attached to $\mathrm{Si}_{43} \mathrm{H}_{48}$, the appearance of a dual-band emission with maxima centered at $\sim 356 \mathrm{~nm}$ and $\sim 470 \mathrm{~nm}$ can be observed, as shown in Figure S9(b). Upon $\left(\mathrm{H}_{2} \mathrm{O}\right)_{5}$ adsorption on $\mathrm{Si}_{43} \mathrm{H}_{48}$, compared with that in the gas phase of $\mathrm{Si}_{43} \mathrm{H}_{48}$, there is a strong intensity decrease with the main peak position at $\sim 355 \mathrm{~nm}$.

(a)

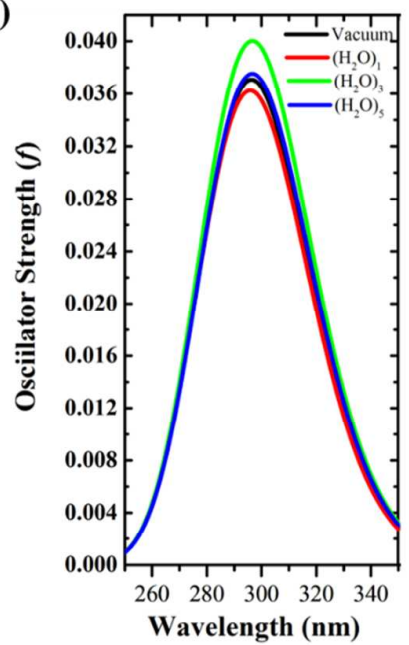

(b)

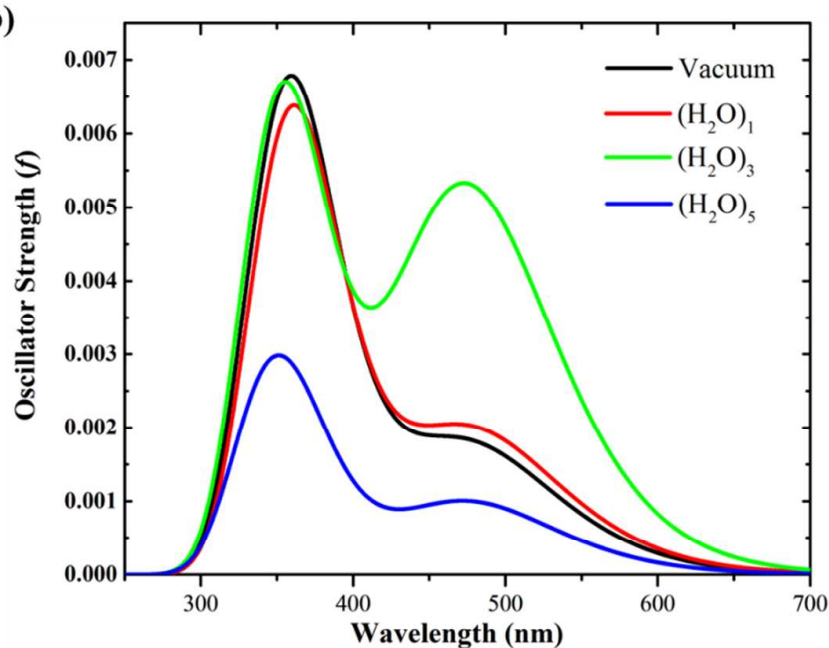

Figure S9. (a) Absorption spectra of vacuum $\mathrm{Si}_{43} \mathrm{H}_{48}$ and water clusters adsorption on this cluster. (b) Fluorescence spectra of vacuum $\mathrm{Si}_{43} \mathrm{H}_{48}$ and water clusters adsorption on this cluster. A Gaussian function with the full width at half maximum $(0.66 \mathrm{eV})$ is used to simulate a finite broadening.

The PL spectra are also determined on the $\mathrm{Si}-\mathrm{Si}$ dimer. Comparison of $\mathrm{Si}-\mathrm{Si}$ bond lengths of $\mathrm{Si}_{43} \mathrm{H}_{48}$ in ground states and excited states, the $\mathrm{Si}$-Si dimer distance shows a stretch about $0.02 \AA$ in the vacuum (Table S5), and this Si-Si dimer is displayed large yellow spheres in the inset of Figure S10. Same situations could be found in the $\left(\mathrm{H}_{2} \mathrm{O}\right)_{1}$ adsorbed on $\mathrm{Si}_{43} \mathrm{H}_{48}(0.03 \AA)$. But, for the $\left(\mathrm{H}_{2} \mathrm{O}\right)_{3}$, the bond length of Si-Si dimer under excitation is stretched about $0.08 \AA$ (Table. S5). Contrary to the large stretch of $\left(\mathrm{H}_{2} \mathrm{O}\right)_{3}$, with the $\left(\mathrm{H}_{2} \mathrm{O}\right)_{5}$ adsorption on Si QDs, this Si-Si dimer distance of excited-state configurations only shows an extension about $0.02 \AA$.

Table S5. Si-Si dimer distances for vacuum $\mathrm{Si}_{43} \mathrm{H}_{48}$ and water molecule clusters adsorption on $\mathrm{Si}_{43} \mathrm{H}_{48}$ in ground state $\left(d_{G}\right)$ and excited state $\left(d_{E}\right)$. The difference between $d_{\mathrm{G}}$ and $d_{\mathrm{E}}$ is shown by $\Delta d$. All values are in $\AA$. This Si-Si dimer is displayed by yellow spheres in the inset of Figure S10.

\begin{tabular}{ccc|c|c}
\hline Cluster & Vacuum & $\left(\mathrm{H}_{2} \mathrm{O}\right)_{1}$ & $\left(\mathrm{H}_{2} \mathrm{O}\right)_{3}$ & $\left(\mathrm{H}_{2} \mathrm{O}\right)_{5}$ \\
\hline$\Delta d$ & 0.02 & 0.03 & 0.08 & 0.02 \\
\hline \hline
\end{tabular}

In order to understand the different stretch of $\mathrm{Si}$-Si dimer distance for water clusters adsorption on $\mathrm{Si}_{43} \mathrm{H}_{48}$, as the electric dipole moment $(\mu)$ of $\mathrm{Si}_{43} \mathrm{H}_{48}$ shown in Figure 
$\mathrm{S} 10$, the direction of dipole moment vector in $\left(\mathrm{H}_{2} \mathrm{O}\right)_{1}$ and $\left(\mathrm{H}_{2} \mathrm{O}\right)_{5}$ adsorption on the surface of $\mathrm{Si}_{43} \mathrm{H}_{48}$ is parallel to the surface of $\mathrm{Si}_{43} \mathrm{H}_{48}$, while the direction of dipole moment vector in $\left(\mathrm{H}_{2} \mathrm{O}\right)_{3}$ adsorption on the surface of $\mathrm{Si}_{43} \mathrm{H}_{48}$ is perpendicular to the surface of $\mathrm{Si}_{43} \mathrm{H}_{48}$. Comparison of the orientation of electric dipole moment with $\left(\mathrm{H}_{2} \mathrm{O}\right)_{1}$, $\left(\mathrm{H}_{2} \mathrm{O}\right)_{3}$ and $\left(\mathrm{H}_{2} \mathrm{O}\right)_{5}$ adsorption on $\mathrm{Si}_{43} \mathrm{H}_{48}$, it suggests that the $\mathrm{Si}-\mathrm{Si}$ dimer distances is influenced by water molecules.
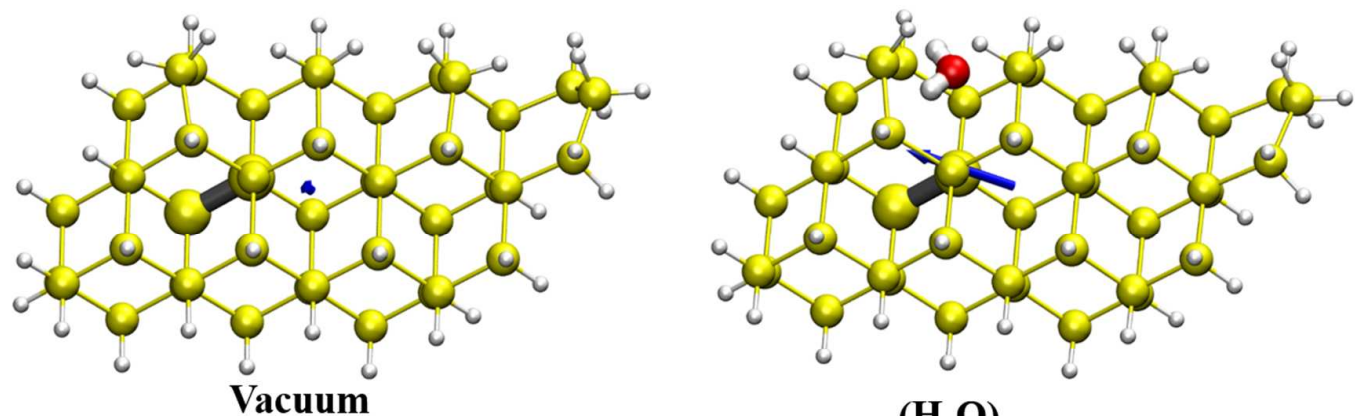

$\left(\mathrm{H}_{2} \mathrm{O}\right)_{1}$

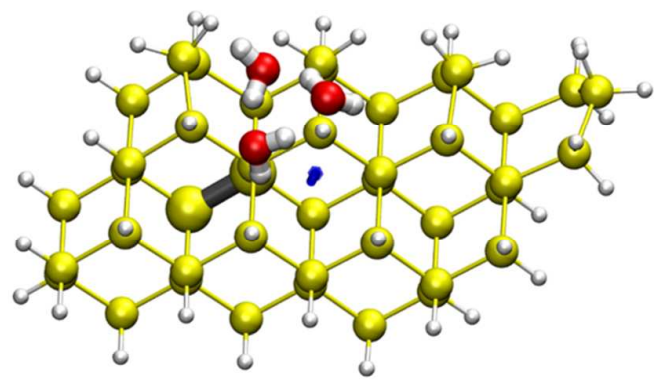

$\left(\mathrm{H}_{2} \mathrm{O}\right)_{3}$

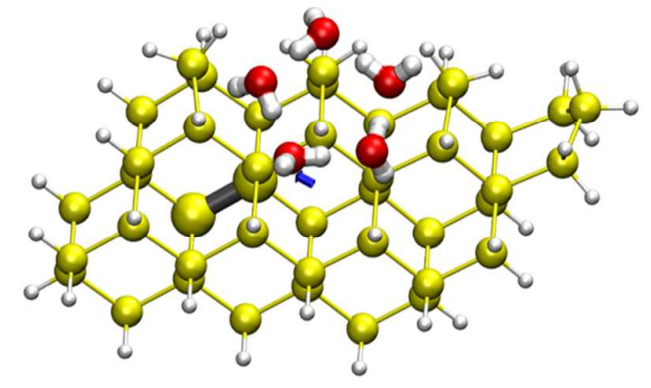

$\left(\mathrm{H}_{2} \mathrm{O}\right)_{5}$

Figure S10. The geometry optimized structures of vacuum $\mathrm{Si}_{43} \mathrm{H}_{48},\left(\mathrm{H}_{2} \mathrm{O}\right)_{1}$, $\left(\mathrm{H}_{2} \mathrm{O}\right)_{3}$ and $\left(\mathrm{H}_{2} \mathrm{O}\right)_{5}$ adsorption on this cluster in ground state. Electric dipole moment $(\mu)$ is represented by the blue solid thick. Color settings are same as the Figure S2.

\section{Reference}

(1) Itoh, U.; Toyoshima, Y.; Onuki, H.; Washida, N.; Ibuki, T. Vacuum Ultraviolet-Absorption Cross-Sections of SiH4, GeH4, Si2H6, and Si3H8. J. Chem. Phys. 1986, 85, 4867-4872.

(2) Wang, X.; Zhang, R. Q.; Niehaus, T. A.; Frauenheim, T.; Lee, S. T. Hydrogenated Silicon Nanoparticles Relaxed in Excited States. J. Phys. Chem. C 2007, 111, 12588-12593.

(3) Maheshwary, S.; Patel, N.; Sathyamurthy, N.; Kulkarni, A. D.; Gadre, S. R. Structure and Stability of Water Clusters $\left(\mathrm{H}_{2} \mathrm{O}\right)(\mathrm{n}), \mathrm{n}=8-20$ : An ab Initio Investigation. J. Phys. Chem. A 2001, 105, 10525-10537.

(4) Silvestrelli, P. L.; Toigo, F.; Ancilotto, F. Interfacial Water on Cl-and H-terminated Si (111) Surfaces from First-Principles Calculations. J. Phys. Chem. B 2006, 110, 12022-12028.

(5) Lange, B.; Posner, R.; Pohl, K.; Thierfelder, C.; Grundmeier, G.; Blankenburg, S.; Schmidt, W. G. Water Adsorption on Hydrogenated Si(111) Surfaces. Surf. Sci. 2009, 603, 60-64.

(6) Silvestrelli, P. L.; Toigo, F.; Ancilotto, F. van der Waals Effects in Interfacial Water on the Cl- and H-Terminated Si(111) Surfaces. J. Phys. Chem. C 2009, 113, 17124-17131. 
(7) Hmiel, A.; Xue, Y. Water Adsorption on Hydrogen-Passivated Silicon Nanowires from Density Functional Theory with Dispersion Correction. Phys. Rev. B 2011, 83, 033304.

(8) Johnson, E. R.; Keinan, S.; Mori-Sanchez, P.; Contreras-Garcia, J.; Cohen, A. J.; Yang, W. Revealing Noncovalent Interactions. J. Am. Chem. Soc. 2010, 132, 6498-6506.

(9) Franceschetti, A.; Pantelides, S. T. Excited-State Relaxations and Franck-Condon Shift in Si Quantum Dots. Phys. Rev. B 2003, 68, 033313.

(10) Jensen, F. Introduction to Computational Chemistry. John Wiley \& Sons, Ltd., 2013.

(11) Allan, G.; Delerue, C.; Lannoo, M. Nature of Luminescent Surface States of Semiconductor Nanocrystallites. Phys. Rev. Lett. 1996, 76, 2961-2964. 